\title{
Mechanical and Optical Properties of Thin Film Titanium Nitride (TiN) Resulting from Deposition DC Sputtering
}

\author{
Andre Yoan Setyanjana ${ }^{{ }^{*},}$, Asih Melati ${ }^{1}$, Ihwanul Aziz ${ }^{2}$ \\ ${ }^{1}$ Physics Departement, Faculty of Science and Technology, UIN Sunan Kalijaga \\ Jl. Marsda Adisucipto No. 1 Yogyakarta 55281, Indonesia. Tel. + 62-274-540971, Fax. + 62-274-519739 \\ ${ }^{2}$ Science and Accelerator Technology Center, National Nuclear Energy Agency of Indonesia (PSTA-BATAN) Jl. Babarsari, Yogyakarta 55281 \\ *Email: andresetyanjana.0401@gmail.com
}

\begin{abstract}
Titanium nitride (TiN) thin film was successfully grown on the surface of stainless steel 304 (SS 304) and preparate glass using the direct current sputtering method. The fabrication was done at high voltage $2.5 \mathrm{kV}$, sputtering current $40 \mathrm{~mA}$, and deposition time 1 hour. The characterization was carried out using a Micro Hardness Tester and UV-Vis Spectrophotometer. Based on mechanical properties, the hardness results of deposition on SS 304 obtained vickers hardness value of 153.59 HVN and thin film thickness was preparate glass $172.61 \mathrm{~nm}$. Whereas optical properties, from testing the transmittance of thin films TiN measured at a wavelength range of $300 \mathrm{~nm}-800 \mathrm{~nm}$, the thin film TiN optical gap energy is $3.51 \mathrm{eV}$.
\end{abstract}

Keywords: Band gap, Sputtering DC, thin film TiN, Vickers hardness

\section{INTRODUCTION}

The thin films is a layer of very thin material that is between the nanometer to millimeter scale. Thin film making has enormous benefits in the material world, including coating materials to cover the weaknesses of coated materials, preparing new materials before being fabricated and developing new materials.

Titanium Nitride (TiN) is material with a promising wide band gap. TiN has the characteristics of low resistivity, transmission that is rather high in the visible light range, high reflectance in the infrared spectrum region, high hardness, high wear resistance, good chemical inertia, and good corrosion resistance (Kiran et al., 2008).

In addition, TiN is a hard mechanical compound and is often used for coating on a material to improve the hardness. Widely used in medical equipment such as scalpels and orthopedics because it is non-toxic. In appearance, the TiN is golden in color with a melting point of $2950{ }^{\circ} \mathrm{C}$ (Talu et al., 2015).

The application of the thin film TiN is very diverse, so it is interesting to study, its uses include: in optical filters, thin layers on resistors, decoration layers, protection layers, and others (Yao et al., 2002). The most basic manufacture or fabrication of TiN for applications is TiN in the form of thin layers. Fabrication of thin films at the moment is very possible for wide applications, because thin films have properties that can be modified in accordance with the device to be made (Solovan et al., 2014). Therefore, thin film research is continuously carried out to get better characteristics (Chen et al., 2012). Some of the methods used include: spin coating, chemical deposition solution (CDS), nitriding, sputtering, pulse laser ablation (PLAD), and others (Zhao et al., 2008).
The process of growing a thin film using sputtering method has several advantages including, a simple growth process, low operating costs, a large deposition rate, can produce thin layers of material that has a high melting point, sputtering material has good durability or physical resistance so it is more efficient, and the thickness of the thin film produced can be controlled with the time of deposit at the time of manufacture (Bambang, 2011).

Based on the type of material to be deposited and the tool system used, sputtering has a variety of methods, including direct current sputtering. Direct current sputtering method is the simplest method for growing thin film layers. In this process the electrical voltage is needed to make high-energy particles, which are used in direct current voltages.

In this study, thin film TiN was grown using direct current sputtering method. Then, layer was characterized by mechanical properties about Vickers hardness value using Micro-hardness Tester Vickers and optical properties about transmittance values using UV-Vis Spectrophotometer and the data were calculated using the Swanepoel equation and the Tauc Plot method to determine the optical band gap energy.

\section{MATERIALS AND METHODS}

The research was carried out in four stages. The first stage is preparation. The material used is transparent glass substrate, stainless steel 304 substrate (SS 304), titanium plate target, water, alcohol, detergent, autosol, nitrogen gas, and argon gas. While the tools used are sandpaper, glass cutter, $100 \mathrm{ml}$ measuring cup, polish machine, ultrasonic cleaner machine, hair drier, DC sputtering tools, Micro-hardness Testes Vickers, and 
UV-Vis Spectrophotometer. Preparation is carried out to clean the dirt and smooth the surface of the substrate which will be grown with thin film TiN on surface. The process is a glass substrate cut to $1 \times 2 \mathrm{~cm}$ and SS 304 substrate $1 \mathrm{~cm}$ in diameter until sanded, then polish and autosol until smooth and clear. After that, the substrate is cleaned with alcohol and detergent using ultrasonic cleaner for 30 minutes, to remove the sticky oil content, then dry it with a hair drier and substrate ready for use.

The second stage is preparing the substrate and target. The target used is titanium plate and the substrate used is SS 304 and transparent glass. Substrate is placed in the bottom position and the target is placed at the top position in the vacuum chamber of the sputtering device, then closed until it is tight.

The third stage is the creation of thin film using the DC sputtering method. This tool consists of 4 main components, that is vacuum chamber, vacuum pump, gas system, and DC voltage. The process is after substrate at anode and target at cathode is installed in the chamber, then the vacuum is applied with a pressure of $2.7 \times 10^{-2} \mathrm{mBar}$ which aims to clean the chamber from the presence of other gases which disrupt the process and results of deposition. After reaching, argon gas is flowed in the chamber then given high voltage about $2.5 \mathrm{kV}$ and direct current around $40 \mathrm{~mA}$ to make high-energy particles. The electric field then occurs which causes electrons to be released into the anode, and crushes argon gas inside the system, resulting in ionization and the atoms in the target are released, these atoms will form a thin film on the substrate installed at the anode. This process is carried out for 1 hour, after which the argon gas flow is closed again.

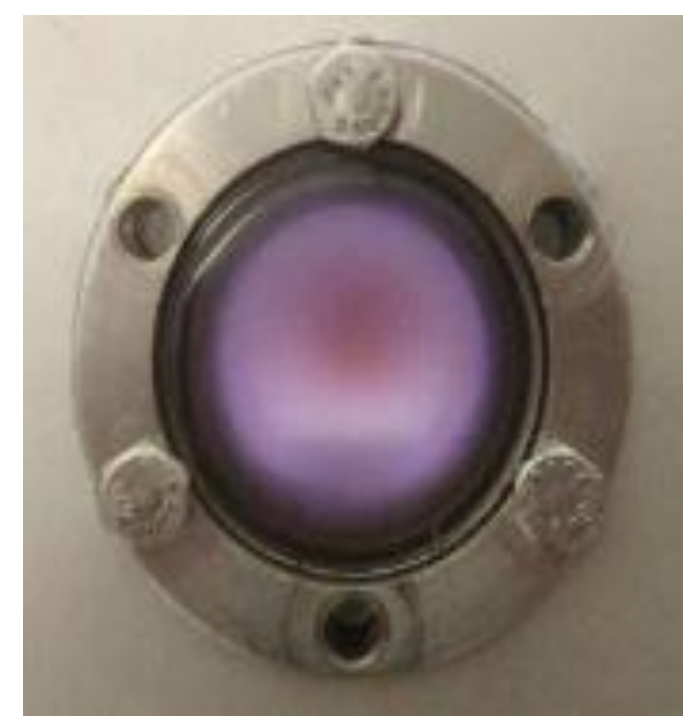

Figure 1. Plasma deposition process.

The fourth stage is characterization. Characterization was carried out using the Microhardness Tester tool to measure the value of hardness before or after deposition and the UV-Vis
Spectrophotometer to measure the transmittance value on the thin film formed on the glass surface. This transmittance value will be used to determine the optical band gap energy of the thin film TiN that has been successfully grown.

\section{Determine the Vickers Hardness}

Vickers hardness value is defined as the material divided by the extent of the pyramid (indentor) footprint in $\mathrm{kg} / \mathrm{mm}^{2}$ and the magnitude of approximately three times the yield stress for metals that do not experience hardening.

In Vickers hardness test, the surface of the test object is pressed with a pyramid-shaped diamond penetrator which is essentially square. The angle between two inclined planes facing each other is $136^{\circ}$. Vickers hardness rate is defined as the load divided by the surface area of the curve. In practice, the area is calculated from the macroscopic measurement of the diagonal length of the trace, which can be mathematically determined from the equation,

$$
V H N=\frac{2 P \sin \frac{\theta}{2}}{\mathrm{~d}^{2}}
$$

With, $\mathrm{P}$ is the load used $(\mathrm{kg}), \mathrm{d}$ is the average diagonal length of the curve (mm), and $\Theta$ is the opposite angle of the diamond surface $\left(136^{\circ}\right)$.

\section{Determine Optical Band Gap}

The results of the measurement of optical transmittance using UV-Vis spectrophotometer in the wavelength range from $300 \mathrm{~nm}-800 \mathrm{~nm}$.

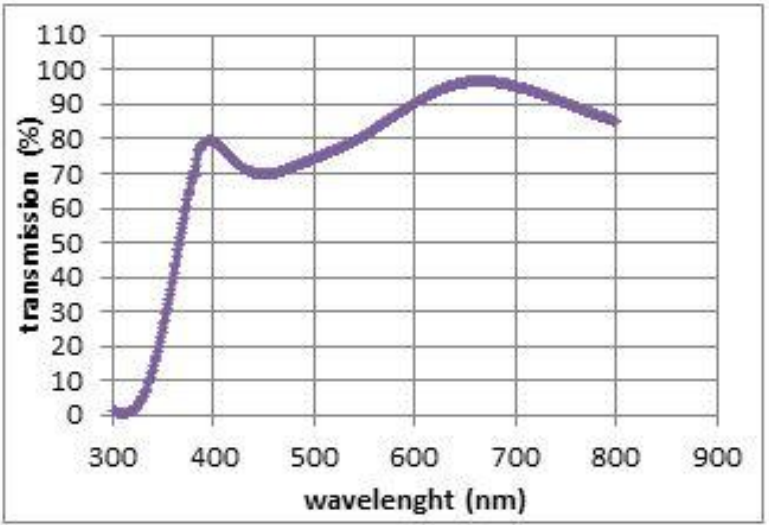

Figure 2. Correlation wavelength and transmittance value of thin film TiN.

The value of the optical band gap on the thin film TiN can be determined by processing the data of wavelength correlation with the percentage of transmittance that has been measured using UV-Vis spectrophotometer. The next step is to determine the optical band energy in the thin film TiN, first determine the maximum transmittance value (TM) and minimum transmittance (Tm), layer thickness (d), refractive index (n), absorption coefficient (a), and then can be known using the Tauc Plot method. 


\section{Refractive Index (n)}

Thin film refractive index can be calculated using equations (2) and (3).

$$
\begin{aligned}
& \mathrm{N}=2 n \mathrm{~s} \frac{T M-T m}{T M \cdot T m}+\frac{n \mathrm{~s}^{2}+1}{2} \\
& n=\sqrt{N+\sqrt{N^{2}-n} \mathrm{~s}^{2}}
\end{aligned}
$$

$n s$ that the glass refractive index is 1.51 . The results of the calculation of the refractive index will be used to calculate the thickness value with equation (4).

\section{Thickness (d)}

$$
d=\frac{\lambda_{1} \lambda_{2}}{2\left(\lambda_{1} \cdot \mathrm{n}_{2}-\lambda_{2} \cdot \mathrm{n}_{1}\right)}
$$

$\lambda_{1}$ is the wavelength at the first peak, while $\lambda_{2}$ is the wavelength at the second peak. After the thickness value of the thin layer of $\mathrm{TiN}$ is known, the value is used to calculate the absorption coefficient with equation (5).

\section{Absorption Coefficient}

Absorption coefficient value can be calculated by substituting the thickness value (d) and the transmittance value $(\mathrm{T})$ with the fixed interval into equation (5).

$$
\alpha=-\frac{1}{d} \ln T
$$

\section{Tauc Plot Method}

The use of this method is carried out by extrapolating from the graph of the relationship of absorption energy (hv) as abscissa and $(\alpha h v)^{\mathrm{n}}$ as ordinate to form an intersection with the energy axis so that the value of the optical band gap can be obtained. The value ho is calculated using equation (6), where $\mathrm{h}$ is the planck constant $6.63 \times 10^{-3^{4}} \mathrm{~J} . \mathrm{s}, \mathrm{c}$ is the speed of light $3 \times 10^{8}$ $\mathrm{m} / \mathrm{s}$ and $\lambda$ is the wavelength of $3 \times 10^{-9}$ to $8 \times 10^{-9} \mathrm{~m}$.

$$
\mathrm{hu}=\mathrm{h} \frac{c}{\lambda}
$$

Using equation (7) which is the swanepoel equation to calculate the band gap value.

$$
\alpha h v=A(h v-E g)^{\mathrm{n}}
$$

$\mathrm{n}=$ type of transmission (on TiN glass substrate is a direct transmission that is $n=1 / 2$ ) which can be reduced as follows.

$$
\alpha h v=\sqrt{A(h v-E g)} /(\alpha h v)^{2}=A(h v-E g)
$$

\section{RESULTS AND DISCUSSION}

Thin film TiN can be grown well on a glass substrate with a deposition time of an 1 hour. The layer formed has a golden yellow color that is very thin as the color of titanium metal.

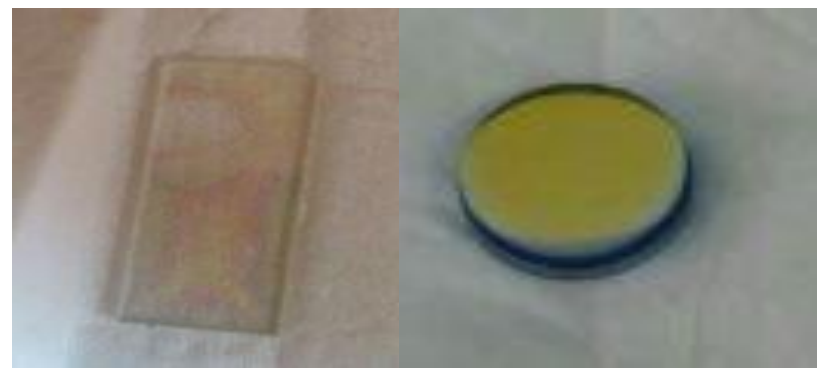

Figure 3. Deposition substrate.

\section{Hardness}

The hardness of the surface metal materials at each tracking location will vary due to surface smoothness, porosity, treatment types, and differences in alloying elements. Diagonal trajectory (d) which is longer in a test material gives the understanding that the value of material hardness is low, whereas a shorter diagonal gives an understanding that the value of material hardness is high. The greater the burden, the diagonal indentation $(d)$ the greater the other side, the greater the diagonal of the indentation, the lower the value of hardness. This is related to the resistance of the material to the deformation by the indenter.

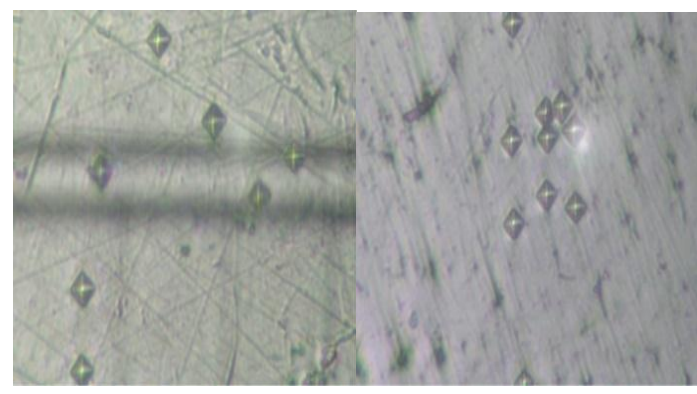

Figure 4. CCD camera image on indented results before deposition (left) and after deposition (right).

Vickers hardness value is known to perform horizontal and vertical diagonal measurements at each point of indentation on SS 304 substrate both before and after deposition of thin film TiN.

Table 1. Vickers hardness value SS 304 before deposition of thin film TiN.

\begin{tabular}{llcl}
\hline Point & \multicolumn{2}{c}{ Diagonal Size } & $\begin{array}{l}\text { Hardness } \\
(\mathbf{H V N})\end{array}$ \\
\cline { 2 - 3 } & $\begin{array}{l}\text { Diagonal 1 } \\
\left(\mathbf{1 0}^{-\boldsymbol{6}} \boldsymbol{m}\right)\end{array}$ & $\begin{array}{l}\text { Diagonal 2 } \\
\left(\mathbf{1 0}^{\left.-\boldsymbol{6}_{\boldsymbol{m}}\right)}\right.\end{array}$ & \\
\hline 1 & 8,84 & 8,80 & 118,9 \\
2 & 9,20 & 8,70 & 115,3 \\
3 & 8,85 & 8,80 & 119,0 \\
4 & 8,70 & 9,06 & 117,5 \\
5 & 8,80 & 8,85 & 119,0 \\
6 & 8,67 & 8,84 & 120,9 \\
7 & 9,07 & 8,69 & 117,5 \\
8 & 8,68 & 9,14 & 116,7 \\
9 & 8,70 & 8,91 & 119,5 \\
10 & 8,68 & 9,09 & 116,7 \\
11 & 9,07 & 8,71 & 117,3 \\
12 & 8,67 & 8,90 & 120,1 \\
13 & 9,22 & 8,69 & 115,6 \\
14 & 8,79 & 9,15 & 115,2 \\
15 & 8,75 & 9,08 & 116,6 \\
Average & & & $\mathbf{1 1 7 , 7 2}$ \\
\hline
\end{tabular}


Table 2. Vickers hardness value SS 304 after deposition of thin film TiN.

\begin{tabular}{llll}
\hline Point & \multicolumn{2}{c}{ Diagonal Size } & $\begin{array}{l}\text { Hardness } \\
\text { (HVN) }\end{array}$ \\
\cline { 2 - 3 } & $\begin{array}{l}\text { Diagonal 1 } \\
\left(\mathbf{1 0}^{\left.-\boldsymbol{~}_{\boldsymbol{m}}\right)}\right.\end{array}$ & $\begin{array}{l}\text { Diagonal 2 } \\
\left(\mathbf{1 0 ^ { - }} \boldsymbol{~} \boldsymbol{m}\right)\end{array}$ & \\
\hline 1 & 7,85 & 7,60 & 155,7 \\
2 & 7,99 & 7,46 & 155,3 \\
3 & 7,89 & 7,51 & 156,3 \\
4 & 7,95 & 7,75 & 150,4 \\
5 & 7,99 & 7,46 & 155,3 \\
6 & 7,74 & 7,73 & 154,9 \\
7 & 7,84 & 7,84 & 151,6 \\
8 & 7,62 & 7,66 & 158,8 \\
9 & 7,85 & 7,85 & 151,2 \\
10 & 7,56 & 7,98 & 153,5 \\
11 & 7,70 & 7,70 & 156,3 \\
12 & 7,72 & 7,94 & 151,2 \\
13 & 7,90 & 7,84 & 149,7 \\
14 & 7,75 & 7,96 & 150,2 \\
15 & 7,67 & 7,87 & 153,5 \\
Average & & & $\mathbf{1 5 3 , 5 9}$ \\
\hline
\end{tabular}

From the results of the research obtained the value of hardness before being given the surface treatment of DC sputtering process that is equal to $117.72 \mathrm{HVN}$ and after being treated the surface becomes 153.59 HVN. This proves that the level of hardness of the material before and after the treatment of the sputtering process is increased by $35.87 \mathrm{HVN}$ and affects the surface structure.

\section{Optical Band Gap}

After calculation, the refractive index of the TiN film on the glass substrate is 1.93176 and 2.29396. The thickness is $17.2614 \times 10^{-8} \mathrm{~m}$, so that the absorption coefficient (a) and absorption energy (hv) can be seen in table 3.

Table 3. The value of absorbing coefficient of thin film TiN.

\begin{tabular}{|c|c|c|c|c|}
\hline$\lambda(\mathrm{nm})$ & $a\left(m^{-1}\right)$ & hv(J.s)x10 ${ }^{-19}$ & hv (eV) & $(\mathrm{ahv})^{2}$ \\
\hline 300 & 24729015,632 & 6,6300 & 4,138446 & $1,04734 \mathrm{E}+16$ \\
\hline 325 & 21524587,326 & 6,1200 & 3,820104 & $6,76114 \mathrm{E}+15$ \\
\hline 350 & 7998597,969 & 5,6828 & 3,547329 & $8,05064 \mathrm{E}+14$ \\
\hline 375 & 2603519,865 & 5,3040 & 3,310757 & $7,42979 \mathrm{E}+13$ \\
\hline 400 & 1343606,772 & 4,9725 & 3,103522 & $1,73882 \mathrm{E}+13$ \\
\hline 425 & 1845415,256 & 4,6800 & 2,921256 & $2,90621 \mathrm{E}+13$ \\
\hline 450 & 2083660,854 & 4,4200 & 2,758964 & $3,30481 \mathrm{E}+13$ \\
\hline 475 & 1953971,307 & 4,1874 & 2,613525 & $2,60789 \mathrm{E}+13$ \\
\hline 500 & 1723234,895 & 3,9780 & 2,483068 & $1,83091 \mathrm{E}+13$ \\
\hline 525 & 1491586,850 & 3,7885 & 2,365094 & $1,24450 \mathrm{E}+13$ \\
\hline 550 & 1232183,557 & 3,6164 & 2,257107 & $7,73491 \mathrm{E}+12$ \\
\hline 575 & 896681,210 & 3,4591 & 2,159108 & $3,74822 \mathrm{E}+12$ \\
\hline 600 & 595578,715 & 3,3150 & 2,069223 & $1,51877 \mathrm{E}+12$ \\
\hline 625 & 349829,103 & 3,1824 & 1,986044 & $4,82714 \mathrm{E}+11$ \\
\hline 650 & 214802,590 & 3,0600 & 1,910052 & $1,68333 \mathrm{E}+11$ \\
\hline 675 & 200391,873 & 2,9466 & 1,839517 & $1,35884 \mathrm{E}+11$ \\
\hline 700 & 279490,164 & 2,8414 & 1,773352 & $2,45653 \mathrm{E}+11$ \\
\hline 725 & 419163,952 & 2,7434 & 1,712430 & $5,15221 \mathrm{E}+11$ \\
\hline 750 & 587328,336 & 2,6520 & 1,655378 & $9,45271 \mathrm{E}+11$ \\
\hline 775 & 764299,823 & 2,5664 & 1,601697 & $1,49861 \mathrm{E}+12$ \\
\hline 800 & 929914,591 & 2,4862 & 1,551761 & $2,08226 \mathrm{E}+12$ \\
\hline
\end{tabular}

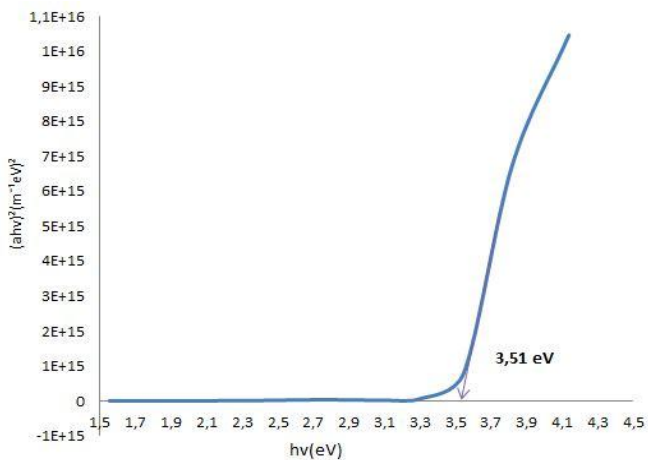

Figure 5. Plot of (ahv)2 against photon energy for thin film TiN.
Then using the Tauc Plot method, by extrapolating from the graph the relationship of absorption energy (hv) as abscissa and $(\alpha h v)^{\mathrm{n}}$ as ordinate to form an intersection with the energy axis to obtain the optical band gap value.

Based on the Tauc method, the plot of the band gap is known as a thin film of Titanium Nitride (TiN) which has been successfully grown through deposition using a DC Sputtering technique which is $3.51 \mathrm{eV}$.

\section{CONCLUSIONS}

TiN thin film grown by direct current sputtering was successfully with a pressure of $2.7 \times 10^{-2} \mathrm{mBar}$, a high 
voltage of $2.5 \mathrm{kV}$ and a direct current of $40 \mathrm{~mA}$ which was carried out for an hour of deposition. On the surface SS $304 \mathrm{~L}$ substrate, there was an increase in material hardness of $35.87 \mathrm{HVN}$ after it was grown with thin film TiN, which was before deposition of $117.72 \mathrm{HVN}$, and after deposition was $153.59 \mathrm{HVN}$. On the surface glass substrate, thin film TiN was successfully grown with a thickness of $172,614 \times 10^{-9} \mathrm{~m}$ and the optical band gap energy was obtained using the Tauc Plot method of 3.51 $\mathrm{eV}$.

\section{REFERENCES}

Bambang S. 2011. Analysis of the mechanical properties of thin film nitride titanium on the camshaft results techniques plasma sputtering. Proceeding PPI PDIPTN, PTAPB BATAN, Yogyakarta. Page 110-114.

Callister. 2007. Materials Science and Engineering An Introduction. John Wiley \& Sons, Inc.

Chen L., Liu MN., Wang SC.,et al. 2012. Preparation of SnS film using solid source deposited by the PECVD method with controllable film characters. Journal Alloys and Compounds,545122-129.Page 1-8.

Hao Yao, Hong S.H, Xu K,. 2002. Thin Films Titanium Nitride, Journal Matter Lett, page 56.
Lei Zhao, Qing Jiang, Jianshe Lian,. 2008. Visible-light photocatalytic activity of nitrogen-doped $\mathrm{TiO}_{2}$ thin film prepared by pulsed laser deposition. Applied Surface Science, 254, page. 4620-4625.

Ohring M, 2002, Material science of thin films deposition and structure, Second edition, San Diego, Academic Press.

Pansila PD, Witit-anun N, Jaminongkan T,. 2012. Preparation of pure anatase $\mathrm{TiO}_{2}$ thin films by DC sputtering technique: study on the effect of oxygen partial pressure, Journal Advanced Materials Research, Vol.463-464, page. 1415-1419.

Pimpabute N, Burinprakhon T.,et al. 2011. Determination of optical constants and thickness of amorphous GaP thin film. Optica Applicata, Vol. XLI, No.1.

Solovan MN, Brus VV, Maistruk EV, Maryanchuk PD,. 2014. Electrical and optical properties of TiN thin films, Inorganic Materia. Fed'Kovich National University, Germany.Vol. 50. No.1 page 40-45 ISSN 0020-1685.

Solovan MN, Brus VV, Maistruk EV, Maryanchuk PD,. 2013. Electrical and photoelectric properties of anisotype n-TiN/p-Si Heterojunctions, Journal Semiconductors. Vol.47. No.9 page 1174.

Stefan Talu., et al. 2015. Surface morphology of titanium nitride thin films synthesized by DC reactive magnetron sputtering. Wroclaw University of Technology, Poland.

Tauc J,et al,. 1966. Optical Properties and electronic structure of Ge phys Stat. Sol. 15,627. 
THIS PAGE INTENTIONALIY LEFT BLANK 